\title{
Condensaciones ginecológicas. Relaciones entre prácticas médico-clínicas, políticas sexuales y reproductivas y la materialidad de los cuerpos de las mujeres cis en el campo (toco)ginecológico de la Ciudad de Buenos Aires, Argentina
}

Gynecological condensations. Relations between medical-clinical practices, sexual and reproductive policies and the materiality of cis women's bodies in the gynecological field of the City of Buenos Aires, Argentina

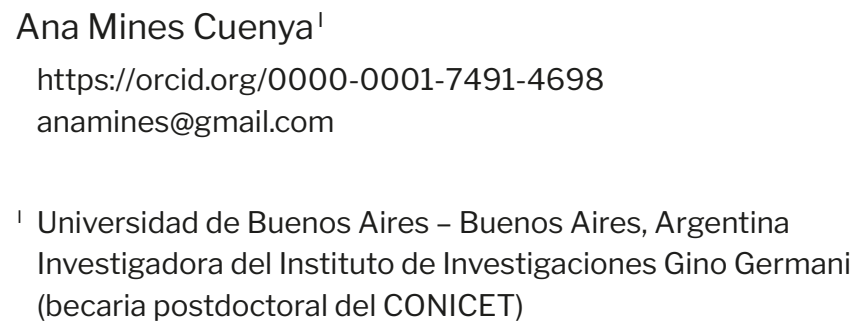




\title{
Resumen
}

El artículo es resultado de una investigación realizada en la Ciudad de Buenos Aires, Argentina. Se analizan las relaciones entre algunas definiciones epistemológicas centrales de la ginecología, prácticas clínicas que tienen lugar en los consultorios y las corporalidades de las mujeres cis. La ginecología es una especialidad particularmente densa, constituida en el entramado de procesos múltiples y heterogéneos como normativas estatales, regulaciones sexo-genéricas y circulación de distintos instrumentos y objetos. En el artículo se analizan tres "condensaciones ginecológicas": 1) La producción de "la salud integral de la mujer" como objeto clínico; 2) la modulación de los procesos corporales de las mujeres cis en "ciclos vitales" organizados en clave reproductiva; 3) los efectos normativos del énfasis preventivo característico de la ginecología. Identificada con los Estudios Sociales en Ciencia y Tecnología, la estrategia metodológica consiste en analizar un conjunto de materiales heterogéneos y en la elaboración situada de categorías.

Palabras clave: condensaciones ginecológicas; regulaciones sexo-genéricas; salud integral de la mujer en Argentina; estudios sociales en ciencia y tecnología.

\begin{abstract}
This article is the result of research carried out in the city of Buenos Aires, Argentina. It analyses the relationships between the central epistemological definitions of gynaecology as a medical speciality, the clinical practices that take place in clinics and the corporealities of cis women. Gynaecology is a particularly dense speciality, constituted in the interweaving of multiple and heterogeneous processes such as state regulations, sex-gender regulations, circulation of different instruments and objects. The article analyses three "gynaecological condensations": 1) The production of "women's integral health" as a clinical object; 2) the modulation of cis-women's bodily processes in "life cycles" organised in a reproductive key; 3) the normative effects of the preventive emphasis characteristic of gynaecology. Identified with Social Studies in Science and Technology, the methodological strategy consists of analysing a set of heterogeneous materials and the situated elaboration of categories.
\end{abstract}

Keywords: gynecological condensations; sex-generic regulations; comprehensive women's health in Argentina; social studies in science and technology. 


\section{Introducción: presentación del problema ${ }^{1}$}

De manera extendida, la (toco)ginecología se define como una especialidad dedicada al abordaje de la "salud integral de la mujer". Se trata de un campo clínico amplio, denso y complejo, resultado de la yuxtaposición de diversos procesos y actores heterogéneos. Además, es una especialidad médica clave en el desenvolvimiento de regulaciones biopolíticas que ubican a los cuerpos de mujeres cis heterosexuales en un lugar protagónico. Como veremos a lo largo del artículo, utilizo el paréntesis en el prefijo "toco" para dar cuenta de las tensiones referidas a la fusión, o no, de la ginecología con la obstetricia.

El objetivo del presente artículo es analizar las relaciones entre las definiciones epistemológicas y categorías propias del campo (toco)ginecológico, las prácticas clínicas que médicos/as ponen en juego en los consultorios y los procesos corporales de las mujeres cis $^{2}$ en Buenos Aires, Argentina. Pretendo indagar en las articulaciones entre estas dimensiones, epistemológicas, prácticas y ontológicas, y sus efectos en el control y la regulación de las capacidades gestantes de las mujeres cis, según un patrón teleológico ajustado a un modelo de familia heteronormado. Para esto voy a valerme de lo que entiendo por "condensaciones ginecológicas", concepto que explicaré al final de la introducción.

El objetivo señalado parte de tres supuestos: 1) En tanto especialidad médica, la (toco)ginecología consiste en un saber y hacer histórico, situado y, por lo tanto, contingente (Rohden, 2001). 2) Las categorías, prácticas médicas, objetos clínicos de esta especialida, así como los procesos que tienen lugar en los cuerpos de las mujeres cis, se relacionan entre sí productivamente, es decir, tienen un carácter consustancial. Los cuerpos no son simples receptáculos de los efectos normativos de las prácticas médicas, sino que participan

1 Agradezco a quienes realizaron la revisión anónima, al equipo editorial de la revista y a quienes coordinaron el número sobre Governança reprodutiva por los valiosos comentarios para mejorar este artículo.

2 Por mujeres cis me refiero a aquellas que conservan la identidad de género que les fue atribuida al nacer, es decir, que no son trans. Como señala Cabral ([2009], p. 48): “Esta oposición distingue entre dos experiencias básicas de la encarnación del género: la de los hombres y las mujeres que viven en el sexo que les fuera asignado al nacer y la de los hombres y las mujeres que en algún momento de su vida cambiaron de sexo". 
activamente en la materialización de esos efectos (Deleuze; Guattari, 2010; Lash, 2007; Macherey, 2011). 3) Las prácticas (toco)ginecológicas no consisten en el abordaje de procesos naturales, innatos o dados de "la mujer". Por el contrario, sugiero que "la mujer" como sujeto homogéneo, así como los procesos sexuales y/o reproductivos que tienen lugar en las vidas de las mujeres cis, se moldean en una relación de permanente hibridación (Latour, 2001) con las prácticas ginecológicas (Mol, 2015).

A diferencia de otras especialidades médicas como la urología o la sexología, la (toco)ginecología supone un campo particularmente denso, resultado de la yuxtaposición de normativas, procesos y actores diversos (Mines Cuenya, 2019). Se destaca la intensa relación con el funcionamiento de normas sexo-genéricas (Butler, 2007; Preciado, 2014), regulaciones que también moldean los cuerpos y vidas de las mujeres (Brown, 2009; Brown et al., 2013b; Freitas, 2008; Martin, 2006; Rohden, 2001, 2007, 2012; Tamburrino et al., 2007).

La (toco)ginecología, en la Ciudad de Buenos Aires, Argentina, se caracteriza por ser un campo profusamente intervenido por el estado nacional, especialmente por el Ministerio de Salud de la Nación. Cabe señalar que buena parte de las normativas nacionales se corresponden con pautas internacionales a las que Argentina ha suscrito, tales como los "Objetivos del Milenio". ${ }^{3}$ Menciono tres ejemplos: el Sistema Nacional de Acreditación de Residencias del Equipo de Salud -que regula la formación en Especialista en Tocoginecología ${ }^{4}-$, el Programa Nacional de Salud Sexual y Procreación Responsable ${ }^{5}$ y el Programa Nacional de Prevención del Cáncer Cervicouterino. ${ }^{6}$ Desde los últimos dos se han elaborado distintos materiales (guías de prácticas clínicas, materiales para equipos de salud y de divulgación general) que atañen directamente al campo (toco)ginecológico y que son difundidos por la prolífera red de organizaciones de profesiones en ginecología y obstetricia.?

3

\section{4}

$$
5
$$

Me refiero especialmente a la Federación de Sociedades de Ginecología y Obstetricia (FASGO), la Sociedad de Ginecología y Obstetricia de Buenos Aires (SOGIBA), la Sociedad de Obstetricia y Ginecología de la Provincia de Buenos Aires (SOGBA), la Sociedad Argentina de Ginecología Infantojuvenil (SAGIJ) y la Asociación Médica Argentina de Anticoncepción (AMAdA). 
Me interesa detectar intersecciones entre diferentes procesos que conviven y conforman el campo (toco)ginecológico. Me refiero, por ejemplo, a las regulaciones estatales, programas ministeriales, métodos anticonceptivos, ciclos menstruales, consultas periódicas de mujeres cis, la regulación de las residencias, las guías de prácticas clínicas, espéculos, los controles en salud, las vaginas, úteros, ovarios, hormonas, la salud sexual y reproductiva, las regulaciones cisheteronormativas, y los cuerpos y procesos de salud y enfermedad, únicos de cada paciente. Llamo a estos entrecruzamientos "condensaciones ginecológicas".

Entiendo a las condensaciones ginecológicas como una herramienta que permite analizar de manera compleja los procesos heterogéneos, multidimensionales e incluso ambivalentes que se yuxtaponen y entrecruzan en la conformación y desenvolvimiento del campo ginecológico. Resonando en los aportes de Deleuze y Guattari (2010), entiendo a las condensaciones ginecológicas como enmarañamientos entre micro y macropolíticas, es decir, entre procesos más sólidos o volátiles, de distinto calibre, alcance y funcionamiento que conforman y se ponen en juego en la relación del campo ginecológico y los cuerpos con los que esta especialidad trata.

En este artículo analizo tres tipos de condensaciones. La primera, consiste en la producción de "la salud integral de la mujer" como objeto clínico. La segunda, refiere al modo en el que las mujeres cis se convierten en pacientes ginecológicas y a la producción, a través de distintos hitos clínicos, de sus trayectorias vitales en términos de "ciclos" organizados en torno a lo reproductivo. La tercera condensación se trata de los efectos normativos vinculados al énfasis preventivo del quehacer ginecológico, es decir, la relevancia de los "controles en salud” y de las prácticas de auto-cuidado identificadas con las mujeres cis.

\section{Consideraciones teórico-metodológicas}

Este artículo se desprende de una investigación desarrollada entre 2012 y 2018 cuyo resultado fue la tesis doctoral titulada Prácticas médico-clínicas y ontologías corporales: sus relaciones en los campos de la ginecología, la urología y la sexología médica en Buenos Aires (Mines Cuenya, 2019). La estrategia teórico-metodológica implementada se hace eco de los estudios sobre el saber 
y el poder de Foucault (1992, 2002, 2008), las epistemologías y los estudios feministas en ciencia y tecnología (Barad, 2014; Fausto-Sterling, 2006; Haraway, 1995; Lykke, 2012) y los Estudios Sociales en Ciencia y Tecnología (Ariza, 2014, 2016; Latour, 2001, 2008; Law, 2015; Mol, 2002, 2013; Mol; Law, 2004). Las decisiones metodológicas partieron del supuesto de que la realidad de los procesos médicos y corporales no está dada a priori. Por el contrario, se asumió que su realidad, plural, semiótica y material se moldea de manera localizada en entramados específicos conformados por agentes humanos y no-humanos, artefactos epistemológicos, prácticas socio-materiales y la proliferación de ontologías múltiples.

En este artículo se analiza un conjunto de 48 materiales heterogéneos recolectados en el período 2016-2018. Se trata de 10 entrevistas a ginecólogos/as (5 mujeres y 5 hombres cis; 9 se desempeñaban en los ámbitos público y privado y 1 solamente en el privado); 4 entrevistas a estudiantes avanzados/as de la carrera de Medicina de la Universidad de Buenos Aires; 11 guías de prácticas clínicas; 5 programas de formación; 4 presentaciones en conferencias/jornadas académicas; 7 artículos académicos publicados por organizaciones profesionales; 2 materiales divulgativos y 5 notas de campo. ${ }^{8}$ La selección de estos materiales no obedeció a un criterio de exclusión establecido a priori, sino que estuvo guiada por una "atención etnográfica" (Ariza, 2016) que privilegió a aquellos documentos, objetos o instrumentos que aparecieron con mayor reiteración y/o intensidad durante el trabajo de campo. Las entrevistas fueron grabadas con el consentimiento de las personas entrevistadas a quienes, luego de transcritas, se les ofreció editarlas. Nadie realizó modificaciones. Las entrevistas han sido codificadas preservando la identidad de las personas entrevistadas.

El proceso analítico se configuró en base a los antecedentes bibliográficos, el trabajo de campo y, específicamente, a las particularidades y formas de agencia específicas de los distintos materiales producidos y recolectados. Se orientó por la exploración del funcionamiento de los pares mujer-hombre, trans-cis, normal-anormal, biológico-adquirido, naturaleza-artificio y por las maneras

8 Ver Argentina (2010a, 2010b, 2010c, 2011, 2014a, 2014b, 2018), Ciudad Autónoma de Buenos Aires (2012); Federación Argentina de Sociedades de Ginecología y Obstetricia (2016, 2017a, 2017b, 2018); Giurgiovich (2017); Holland-Hall (2018); Hospital Italiano de Buenos Aires ([2008]); Katabian; Oizerovich (2017); Provincia de Buenos Aires (2012a, [2012b]); Rademacher et al. (2018); Tilli ([2015a], [2015b]); Universidad de Buenos Aires (2014). 
en las nociones como sexo, sexualidad y reproductivo configuran sentidos y prácticas. El análisis consistió también en la producción situada de conocimiento (Haraway, 1995), es decir, en la elaboración de categorías capaces de dar cuenta de las conexiones presentes en la confección y análisis del objeto de este artículo: las relaciones entre prácticas médico-clínicas, políticas sexuales y reproductivas y la materialidad de los cuerpos de las mujeres cis en el campo ginecológico de la Ciudad de Buenos Aires, Argentina. La noción "condensaciones ginecológicas" es resultado de este ejercicio.

\section{Análisis}

\section{Condensación 1: La "salud integral de la mujer" como objeto clínico de la (toco)ginecología}

En el campo médico, la "salud integral de la mujer" se conforma como el objeto clínico específico de la (toco)ginecología. Además de estar estrechamente relacionada con las nociones de prevención y cuidado, la configuración de este objeto supone el establecimiento de competencias médicas y habilidades clínicas específicas que quienes se especializan en (toco)ginecología deben desarrollar y poner en práctica en su desempeño profesional. El objetivo de este apartado es, justamente, describir las relaciones entre la conformación del objeto clínico y las prácticas (toco)ginecológicas.

\section{Intervenciones estatales en la construcción del objeto clínico (toco)ginecológico}

El campo (toco)ginecológico está intensamente regulado por diversas instancias estatales. El quehacer en los consultorios no es indiferente a las normativas, guías y protocolos producidos, por ejemplo, desde los programas nacionales de Salud Sexual y Procreación Responsable y Prevención del Cáncer Cervicouterino, el Área de Ginecología y Obstetricia de la Dirección Nacional de Maternidad e Infancia y la Dirección de Sida y Enfermedades de Transmisión Sexual. Su lectura y utilización son recomendadas por la profusa red de organizaciones profesionales que componen el campo gineco-obstétrico argentino. 
En 2010, bajo la órbita del Ministerio de Salud de la Nación, se impulsó la regulación del sistema de residencias médicas, especificamente para aquellas especialidades consideradas prioritarias por el Consejo Federeal de Salud. La tocoginecología formaba parte de ese grupo. El documento Marco de referencia para la formación en Residencias Médicas. especialidad Tocoginecología (Argentina, 2010b) (en adelante "documento Marco"), resultado de ese proceso, es el modelo en base al cual se adecuan los programas académicos de los ministerios de salud de la provincia y la ciudad de Buenos Aires.

Las propuestas programáticas de estas tres jurisdicciones, Nación, Provincia y Ciudad de Buenos Aires, establecen lineamientos generales para las residencias y respecto del perfil profesional. Estas coinciden en que la formación debe ser en tocoginecología, es decir, en ginecología y obstetricia, y no solo en ginecología. Como veremos, esta fusión de especialidades no va de suyo ni tampoco es siempre puesta en práctica.

En relación con el perfil profesional, podemos decir que los tres programas analizados impulsan la formación de especialistas capaces de dar cuenta de la "salud de la mujer", focalizando especialmente en lo reproductivo, el embarazo y el parto. Me interesa indagar en las maneras en las que se articulan la noción de "mujer" y de salud con lo reproductivo en relación con la definición del perfil profesional (toco)ginecológico. Para eso, cito un fragmento del documento Marco:

\section{JUSTIFICACIÓN DEL PERFIL}

Hombres y mujeres son afectados de forma diferencial por las políticas económicas, sociales, educativas y de salud. Las mujeres [...] son las que menos capital social, humano y cultural acumulan a lo largo de su vida, y de quienes depende la supervivencia, sanidad y desarrollo de las futuras generaciones. [...]. De los ocho [Objetivos del Milenio], tres están directamente relacionados con las tareas que desarrollarán los futuros Tocoginecólogos:

- Promover la igualdad de género y el empoderamiento de las mujeres.

- Reducir la mortalidad infantil y neonatal.

- Mejorar la salud materna con acceso universal a la salud sexual y reproductiva. (Argentina, 2010b, p. 5).

El documento Marco pone de manifiesto la relevancia que el Estado le asigna a las mujeres cis en las funciones de cuidado, "supervivencia" y "sanidad" social. 
Además, establece a la tocoginecología como brazo estatal operativo en relación con tareas vinculadas a la promoción de la igualdad de género, reducción de la mortalidad infantil y neonatal y al mejoramiento del acceso a la salud sexual y reproductiva.

Las consideraciones del documento Marco se fundamentan en una serie de supuestos sobre las vidas y la salud de las mujeres, caracterizados por su ambivalencia. Por un lado, las identifica como cuidadoras (Costa et al., 2006; Martin, 2006; Vieira, 2002), es decir, como responsables de su propia atención, así como del cuidado de "futuras generaciones". Esta afirmación condensa la idea de que las mujeres, en tanto agentes sanitarios, son responsables de su salud y de la de sus familias. Por otro lado, las identifica como parte de un grupo afectado por desigualdades estructurales y, por tanto, vulnerable y en riesgo (Schwarz, 2010). Según esas consideraciones, las mujeres cis son, al mismo tiempo, cuidadoras-vulnerables, una doble razón para que las distintas instancias estatales promuevan la formación de médicos y médicas capaces de cuidarlas y controlarlas:

[...] se debe lograr el egreso de un profesional capacitado para la atención integral, básica y primaria de la mujer en todas sus etapas evolutivas. (Argentina, 2010b, p. 8).

El toco-ginecólogo es un médico capacitado para abordar [...] el cuidado [...] de la salud de la mujer. El rol social que ocupa [...] lo posiciona como un especialista de referencia de las mujeres en las sucesivas etapas de su ciclo vital. (Provincia de Buenos Aires, [2012b], p. 14).

[La tocoginecología] requiere un enfoque integral en la atención de la salud de la mujer, implementando acciones [...] más allá de su función reproductiva, tales como: educación para la salud, prevención y tratamiento del cáncer génito-mamario, enfermedades cardiovasculares, trastornos de nutrición, salud sexual y reproductiva, enfermedades de transmisión sexual [...] y control prenatal, entre otros. (Ciudad Autónoma de Buenos Aires, 2012, p. 2).

Tal como se lee en los fragmentos citados, los distintos niveles estatales intervienen en la definición y promoción de la (toco)ginecología como especialidad de cabecera de "la mujer" a cargo del abordaje de su "salud integral". Al asumir 
a "la mujer" como una ontología apriorística y generalizable, el Estado lleva a cabo una operación de homogeneización, estabilización y reducción que constriñe la existencia de corporalidades, deseos, estilos de vida, procesos de salud y enfermedad disímiles produciendo y reforzando parámetros corporales e identitarios (Brah, 2004; Butler, 2007; De Lauretis, 1989).

La (toco)ginecología conforma lo que Rohden (2001) entendió como "ciencia de la diferencia" que, a mi entender, podría considerarse como ciencia de la diferencia cisexual. La definición del campo tocoginecológico presupone patrones corporales y sexuales abstractos y comunes que, por un lado, configuran a los procesos de salud y enfermedad que afectan a mujeres y hombres cis como radicalmente distintos. Por otro, excluyen de su campo clínico a la atención de procesos de salud sexual y reproductiva de hombres trans que conservan útero y ovarios y que, inclusive, manifiestan voluntad gestante, así como a las mujeres trans que tienen vaginas. El campo de injerencia de la (toco)ginecología no se define, así, por la atención de personas con cuerpos con capacidad de gestar, en abstracto, sino en tanto cuerpos de "mujer". La supuesta transparencia y asequibilidad de los procesos de salud que definen a "la mujer" son, en parte, resultado del funcionamiento de políticas estatales (Costa et al., 2006; Martin, 2006), de la medicina, en general, de la (toco)ginecología, en particular.

Ahora bien, ¿qué quiere decir "salud integral" para la (toco)ginecología? ¿Cuáles y cómo son las estrategias y herramientas clínicas de las que se vale para su abordaje? Como se señala en los materiales analizados, durante la formación profesional deben incorporarse diversas competencias clínicas:

\section{COMPETENCIA GENERAL:}

Atender a la mujer en las distintas etapas de su vida en los aspectos generales, reproductivos y ginecológicos con una visión integral [...].

\section{Actividades Profesionales [y] Criterios de realización}

[1] Realizar el acompañamiento de la mujer enfatizando la prevención y la promoción de la salud, contemplando la influencia del entorno familiar y social respetando la diversidad cultural en el proceso de salud sexual y reproductiva.

[2] Realizar anamnesis: [considerando] el contexto socioambiental, económico y cultural. [...].

[3] Realizar Examen Clínico: [...] general [...] y genitomamario [...]. 
[4] Conformar diagnóstico [...].

[5] Recomendar y/o tratar: Se pautan controles de salud. Se promueven acciones de educación para la salud. (Argentina, 2010b, p. 8-9, destacados en el original).

\section{COMPETENCIAS}

[1] - Desarrollar actividades de prevención y promoción de la salud de la mujer en todas las etapas del ciclo vital.

[2] - Identificar e intervenir frente a los factores de riesgo poblacionales que puedan afectar la salud de la mujer.

[...]

[4] - Intervenir [...] teniendo en cuenta la especificidad de cada etapa del ciclo vital [...].

[5] • Elaborar diagnóstico y tratamiento de enfermedades ginecológicas y obstétricas [...].

[...]

[10] - Comprender el acto de la consulta médica como un proceso continuo. (Provincia de Buenos Aires, [2012], p. 14).

Según los documentos, la exploración clínica (toco)ginecológica debería ser amplia, capaz de considerar aspectos culturales y familiares y de vincular los procesos de salud y enfermedad con los contextos en los que se producen. La capacidad para realizar este tipo de exploración debería sumarse a las habilidades técnicas específicas para la realización de exámenes físicos y ginecológicos, seguimientos, diagnósticos, tratamientos y algunos tipos de cirugías. Estas competencias, generales y específicas, no son ajenas a los supuestos que identifican a las mujeres cis como cuidadoras-vulnerables. Por el contrario, se organizan de acuerdo a esa premisa.

\section{El abordaje de "la salud integral de la mujer" en los consultorios}

En este apartado analizo las maneras en las que se ponen en juego las habilidades clínicas centrales de la tocoginecología en el ejercicio asistencial. Como veremos, el abordaje de la "salud integral" se relaciona con la posibilidad de atender a las mujeres cis a lo largo de su vida, sin interrumpir esa atención en el momento del embarazo y el parto. Tal como define una ginecóloga: 
La ginecología se dedica a la atención de la mujer, o sea, de todas esas cosas que nos distinguen de un hombre. La atención ginecológica remite a útero, ovarios, vagina, más la parte de mamas. Y lo que refiere al ciclo reproductivo, al embarazo, parto, post parto, o sea, la reproducción, la maternidad, sería más obstetricia. Todos los cambios que se van produciendo desde que la mujer nace hasta que fallece en todas las etapas de su vida, esos eventos y especificidades del cuerpo, son campo de la tocoginecología. (Entrevista a ginecóloga).

Esta especialidad aborda distintos eventos y procesos que tienen lugar en los cuerpos y vidas de las mujeres cis en términos de totalidad (en palabras de la entrevistada la tocoginecología aborda "todos los cambios que se producen en la vida de la mujer"), como un continuum vital organizado en etapas progresivas. Los ciclos menstruales, procesos conceptivos, decisiones anticonceptivas, mamas, ovarios, cuellos de útero son modeladas como parte de procesos regulares que tienen lugar en cuerpos homogéneos. Como señala un profesional

El tocoginecólogo tiene una concepción más global, tiene la posibilidad de atender a la paciente a lo largo de la vida, en todas las etapas, incluso cuando queda embarazada. Como atención es mejor, más integral. Si no, cuando la paciente se embaraza, el ginecólogo tiene que derivarla y volverla a recibir después del parto. Ahora, en la práctica, muchos dejamos de hacer obstetricia porque es mucho ajetreo. (Entrevista a ginecólogo).

Si bien los programas de formación estimulan a la conformación y al ejercicio de la tocoginecología, en la práctica hay profesionales que prefieren separar los campos de la ginecología y obstetricia y, en muchos casos, optar por dedicarse al primero. De hecho, la totalidad de los y las profesionales entrevistados/as habían dejado de atender embarazos y partos:

Hace un año atrás decidí dejar la obstetricia, no más partos, sigo sólo con gineco. La obstetricia es muy desgastante, muy estresante. Tenés que estar corriendo, a cualquier hora, fines de semana, a la noche, a la madrugada, salir a cualquier hora. Es una especialidad para hacerla una época de la vida. (Entrevista a ginecólogo). 
Después de recibida me dedique a la ginecología general y a la obtetricia, pero rápidamente dejé de hacer los partos. Me daban nervios. Y eso me limitaba la posibilidad de disociarme y de tener capacidad operativa. Admiro del trabajo del cirujano y de los obstetras la cosa técnica. La verdad que lo experimenté en carne propia y dije, "no, esto no es para mí". (Entrevista a ginecóloga).

La formación en tocoginecología pautada por los distintos ministerios de salud supone un campo clínico homogéneo, regular, progresivo y asequible a partir de su desenvolvimiento en etapas. Supone también la formación de profesionales capaces de abordarlo de manera global. En efecto, "la atención de la mujer en sus diferentes ciclos vitales" opera como un modelo normativo con efectos en la conformación del campo clínico y en la definición del perfil profesional de tocoginecólogos/as. Sin embargo, en el ejercicio clínico, algunos médicos y médicas introducen discontinuidades a la globalidad de los procesos tocoginecológicos, reorganizándolos en ginecológicos y obstétricos. Esta separación se relaciona con distinto tipo de resistencias, a veces más afectivas (estrés, miedo, "incapacidad de disociarse"), otras veces más prácticas ("tenés que estar corriendo") que tienen lugar en el día a día. Los embarazos y partos conforman episodios intensos, a veces imprevisibles y desgastantes, cuyo abordaje conlleva diferencias significativas respecto de las demandas clínicas que tienen lugar en los consultorios ginecológicos las que, como veremos, se caracterizan su regularidad.

El abordaje de la salud integral de las mujeres cis también se ve discontinuado e, incluso fragmentado, debido a algunas limitaciones prácticas en el abordaje clínico:

Si tenemos que confiar en las historias clínicas que hacemos, nadie cuenta nada y nadie habla de nada que no sean métodos anticonceptivos y PAP. Creo que eso se debe principalmente al factor tiempo. En el Hospital siempre decimos: "no puede ser que no tengamos pacientes con problemas de adicción, que no tengamos..." no sé, consultas en las que salgan los otros problemas de salud de las mujeres. “¿Dónde están?” No sabemos preguntar. (Entrevista a ginecóloga).

Cuando aparece un tema que cuesta, trato de ser amable, de preguntar si hay dudas, sobre todo cuando inician relaciones, “¿alguna duda?”, “¿hay algo que quieras preguntar respecto de tu sexualidad?”, “'ha pasado algo que te llame la 
atención?" Pero bueno, me pasa a mí, como les pasa a muchos médicos, que después que preguntas, tenés que escuchar... Y la consulta dura 15 minutos. Si sale algún tema que la angustia y vos preguntás, después tenés que hacerte cargo. Entonces, en general, se pregunta por cuestiones concretas, sobre las que podemos dar respuestas concretas. Si viniste para control de mamas, mejor no nos metamos con otro tema y resolvamos ese. Correspondería preguntar, pero generalmente no se hace. (Entrevista ginecóloga).

En la práctica clínica, la atención de la "salud integral de las mujeres" está atravesada por dificultades y limitaciones de distinto tipo, que van desde cuestiones de índole subjetiva, falta de herramientas clínicas ("cómo preguntar") e institucionales ("falta de tiempo"). Se trata de la mayor o menor habilidad para poner en consideración aspectos de la vida íntima y emocional de quienes consultan, de las limitaciones prácticas para desarrollar un trabajo interdisciplinario en el marco de un equipo de salud y, también, de los límites institucionales vinculados al espacio y tiempo. Parte de lo que (toco)ginecólogos/as hacen o dejan de hacer se relaciona con las posibilidades clínicas, protocolizadas y sabidas para dar una respuesta y ofrecer alternativas o tratamientos. Asimismo, dar una "respuesta concreta" se configura casi como un mandato, como una condición que, creo, limita las posibilidades de apertura y de exploración clínica.

Por diferentes razones, los aspectos de las vidas, cuerpos, dolencias o malestares que exceden lo génito-mamario, conceptivo o anticonceptivo, suelen quedar por fuera de los registros y abordajes (toco)ginecológicos. Así, la "salud integral de la mujer", se configura como un ideal regulatorio que interviene en el campo (toco)ginecológico a través de la producción de un déficit. Pues, se trata de un modelo de atención que supone prácticas que no suelen realizarse en el quehacer cotidiano de los consultorios.

\section{El campo (toco)ginecológico como ejercicio de ampliación y reducción}

A modo de síntesis de la primera condensación, sugiero que la conformación de la "salud integral de la mujer" en tanto que objeto clínico de la tocoginecología es resultado de un proceso de hibridación entre diferentes elementos (Latour, 2001): definiciones teórico-epistemológicas, habilidades clínicas, demandas en consultorios, instrumentos clínicos, tiempo disponible para la consulta, 
espéculos, nociones vinculadas al rol y respuestas médicas, emociones, subjetividades, aspectos morales. Sugiero que entre estos elementos se trama una gimnasia de "amplificación" y "reducción" (Latour, 2001) constitutiva del campo (toco)ginecológico.

La "salud integral de la mujer" es resultado de un proceso de "amplificación", es decir, de los efectos de un entramado de definiciones y quehaceres que se organiza a través de la identificación de aspectos corporales relacionados con la capacidad gestante, con el ser "mujer", la maternidad y el cuidado. La amplificación consiste en la articulación de los cuerpos con útero, ovarios, vagina con las características que definen a las mujeres cis como cuidadoras-vulnerables, con el rol materno y la responsabilidad de cuidado de la salud propia y familiar, como si todo eso fuera de suyo, naturalizando los efectos normativos de género sobre los cuerpos y vidas de las mujeres cis.

Simultáneamente, opera un proceso de "reducción", resultado de la concatenación de prácticas (toco)ginecológicas y sus efectos en un sentido inverso. Esta especie de encadenamiento modula la diversidad y pluralidad de cuerpos y procesos de salud y enfermedad que afectan a las mujeres cis contrayéndolos y homogeneizándolos entorno a la noción de "mujer". Este proceso, resulta en la identificación cisexista entre "mujer" y órganos reproductivos como útero, ovario, vagina.

Como vimos a lo largo del apartado, la (toco)ginecología identifica su quehacer con los procesos de salud y enfermedad de "mujer". Esta definición supone el moldeamiento de determinados procesos corporales en relación con lo que se supone que es "la mujer". Al mismo tiempo, la producción axiomática de "la mujer" como portadora de una naturaleza gestante opera como matriz epistemológica y como frontera productiva que organiza, a la vez que resguarda, al campo clínico de la (toco)ginecología en términos cis y heterosexistas.

\section{Condensación 2: La construcción de la paciente (toco)ginecológica y de los ciclos vitales como hitos clínicos}

La asistencia de las mujeres cis a los consultorios (toco)ginecológicos, suele iniciarse con la llegada de la menstruación y/o con el inicio de las relaciones sexuales heterosexuales, eventos que marcan el comienzo de una vida y un cuerpo como reproductivos. La relación de las mujeres cis con este campo 
clínico hace que procesos como la menarca, el inicio de relaciones cisheterosexuales, embarazos, partos, puerperio y menopausia se conformen como hitos clínicos, tan íntimos como médicos. Su emergencia produce marcas temporales, es decir, distintos "antes" y "después" que, en términos tocoginecológicos, suponen el inicio y el cierre de distintos "ciclos vitales". ${ }^{9}$ Estos ciclos no son ajenos a procesos sociales más amplios que organizan la vida en etapas como la infancia, adolescencia, adultez y vejez.

Para indagar en la conformación de esos eventos técnico-rituales (Bourdieu, 2000) y en la configuración de los ciclos vitales, veamos algunas características del inicio de las mujeres cis como pacientes ginecológicas y el peso que tiene lo referente a lo reproductivo:

[Es competencia del tocoginecólogo] atender a la mujer en las distintas etapas de su vida en los aspectos generales, reproductivos y ginecológicos con una visión integral con perspectiva de género y derechos. (Argentina, 2010b, p. 9).

En cada etapa es un acompañamiento específico. Con las que se están iniciando sexualmente hay que hablar de qué esperar y qué no. Hay que abrirles espacio para la consulta. Después, en el durante, o sea, cuando ya iniciaron, son sobre todo consultas de control. Una chica de 30 años, por ahí consulta por embarazo, pero si quiere quedar embarazada deja el anticonceptivo y se embaraza. Entonces consulta embarazada o si no lo consigue. Cuando es el caso de alguien que ya tuvo un embarazo y después va a iniciar relaciones, ahí sí surgen preguntas. Hablamos las cosas desde el vamos: "bueno, ya podés empezar a tener relaciones", "puede ser que tengas un poquito de pérdidas, no te asustes". También les digo que tienen que volver a tomar las pastillas porque la fertilidad vuelve enseguida. (Entrevista a ginecóloga).

El campo (toco)ginecológico se organiza sobre el supuesto de que las mujeres cis van a establecer un vínculo permanente con los consultorios médicos durante buena parte de sus vidas. Esta organización presupone que las

9 Maluf (2010) ha analizado las maneras en las que las políticas públicas en salud, así como la industria farmacéutica dan forma a la noción de "ciclo de vida" en relación con la noción de vulnerabilidad, asociada a la adolescencia, embarazo, post-parto, menopausia. 
trayectorias vitales y sexuales de las mujeres se ordenan en ciclos o etapas con características, necesidades y demandas específicas que la (toco)ginecología, de algún modo, debe resguardar y regular. Estos ciclos discurren de manera teleológica: el embarazo es el evento que gravita con la fuerza simbólica y material propia de una finalidad u objetivo, como un parámetro a partir del cual se modelan las otras etapas.

En palabras de Brown et al. (2013a, 2014), en el abordaje ginecológico, las vidas de las mujeres cis se moldean en términos de planificación familiar. Esta especialidad "apunta a proveer anticoncepción para que la maternidad llegue en el momento que el saber experto considera más apropiado, así como para permitir los espaciamientos adecuados de los embarazos" (Brown et al., 2014, p. 677, destacados en el original).

La tocoginecología no es ajena a las marcas que, tal como señala Martin (2006), convierten a los cuerpos de niñas en cuerpos de mujer. Las trasformaciones corporales propias de la adolescencia, así como esas primeras experiencias sexuales, se modulan en la consulta en términos de prevención, cuidado, anticoncepción. Según el documento Consenso de ginecología infanto-juvenil de la Federación Argentina de Sociedades de Ginecología y Obstetricia (en adelante, FASGO) y las entrevistas que cito a continuación, la adolescencia:

Se refiere a una etapa [...] que incluye la transformación del niño/a en adulto. [...] La menarca constituye el hito más significativo del desarrollo puberal, es el anuncio de la posible fertilidad futura [...]. (Federación Argentina de Sociedades de Ginecología y Obstetricia, 2016, p. 1-2).

Me parece importante conectar a las niñas y adolescentes con la genitalidad y lo femenino. Creo que esa es la base de la prevención. Habilitarles la vulva, ponerle nombre a la vulva, que no es vagina, es vulva. Vagina es otra cosa, es vaina y sirve para alojar un pene. (Entrevista a ginecóloga).

ENTREVISTADORA: ¿Hay algún criterio para recomendar anticoncepción según la persona?

MÉDICA: Sí y no. Vas desde lo más fácil, a lo más complejo y depende de la etapa. A alguien que va a iniciarse con las relaciones sexuales le tenés que indicar un método que no tenga que ver con lo genital. No le vas a poner un DIU [dispositivo 
intrauterino] a alguien que todavía no tuvo relaciones. O sea, el espectro de posibilidades se reduce a las pastillas y depende de la edad, a qué pastillas. También están los anillos vaginales. Tampoco se lo vas a dar a una chica que ni inició relaciones sexuales, se lo das a una que ya está canchera, que no tiene drama en meterse el dedo, sacarse el dedo. (Entrevista a ginecóloga).

Desde temprana edad los cuerpos de las mujeres cis se construyen como reproductivos. La menarca se conforma como hito clínico de inicio y punto de anclaje de la relación de las adolescentes con la (toco)ginecología. En efecto, la llegada de la menstruación se define como el punto cero de la "edad ginecológica" (Federación Argentina de Sociedades de Ginecología y Obstetricia, 2016). Las características de la genitalidad, algunas de sus capacidades, fragilidades y potencialidades también son modeladas a través de su relación con el quehacer ginecológico. Aquello que sucede en la consulta médica interviene en las formas en las que las adolescentes se contactan con sus genitales.

En los materiales analizados no son numerosas las menciones a las vulvas, menos aún al clítoris. Por el contrario, las menciones a las vaginas son frecuentes y suelen asociarlas a su penetrabilidad en tanto función natural y primigenia. Salvo excepciones, en los consultorios no se realizan exámenes ginecológicos, o sea, exámenes que involucre el contacto con los genitales, a adolescentes que aún no han tenido relaciones sexuales de penetración heterosexual. Tampoco se les indican métodos anticonceptivos que requieran tocarse los genitales. Estos son indicados a las mujeres que "ya iniciaron relaciones", “a las que están cancheras y no tienen drama en meterse el dedo". Pareciera ser que el primer contacto con esos genitales está reservado para el pene, cuyo debut constituye el hito que habilita a otros tipos de contacto, incluyendo el auto-contacto. Como veremos, las prácticas (toco)ginecológicas actúan como una especie de tamiz que da forma a la sexualidad de las adolescentes:

[Entre las consultas típicas] está el grupo de las que vienen antes de empezar a tener relaciones. Con ellas se hace acompañamiento desde la anticoncepción, se trabajan las dudas y fantasías relacionadas a este inicio. El tema en este momento son sus no definiciones, "bueno, sí, tengo novio, estoy saliendo con un chico" o "no, no estoy saliendo con un chico". Hay una cuestión con el título de novio y con el reconocimiento de que están teniendo relaciones. Para ellas están 
teniendo encuentros y "por tener un encuentro no me va a pasar nada, una vez, y tampoco voy a empezar a tomar pastillas si no sé si lo voy a volver a ver, o si lo voy a ver la semana que viene o qué voy a hacer". Entonces, toda esa cosa media anodina de "estoy teniendo...". O sea, asumir, sí, esto se llama tener relaciones, esto es desarrollar mi sexualidad, que tengo que saber cuidarme, tengo que estar atenta. (Entrevista a ginecóloga).

Las adolescentes están entre el grupo de riesgo más alto de embarazos no planificados. El embarazo muchas veces no planificado, no deseado o inoportuno tiene un impacto negativo sobre la condición física, emocional y económica de la joven. [...]. Hoy en día, pueden elegir el método anticonceptivo que más se adapte a sus necesidades y estilo de vida [...]. No obstante las tasas de embarazos no planificados siguen siendo altas. (Federación Argentina de Sociedades de Ginecología y Obstetricia, 2016, p. 21-22).

Desde temprana edad, el ejercicio sexual se asocia a sus consecuencias reproductivas, por eso "deben asumir" que "eso", es decir, las primeras exploraciones sexuales con un varón cis, se llama "tener relaciones" y que "por eso deben cuidarse", "estar atentas". Las diversas maneras de vivir, sentir, narrar el incipiente ejercicio de prácticas sexuales con otro pasan por la criba material y discursiva de la ginecología. Este pasaje uniformiza cuerpos y experiencias en términos anticonceptivos, moldeando lo "anodino", disperso, ligero de las primeras prácticas sexuales en función de la responsabilidad que implican sus posibles consecuencias reproductivas. En su relación con las consultas (toco)ginecológicas, la experiencia con el propio cuerpo y con la experimentación sexual se formatea en términos de prevención y de responsabilidad (Brown et al., 2013a).

A su vez, lo arriba señalado se yuxtapone con una "preocupación poblacional" referida a las tasas de embarazo adolescentes que la ginecología, en el marco de distintas estrategias estatales, busca evitar. Si consideramos la dimensión moral de esta premisa preventiva, nos vemos en la obligación de "notar el fin de los medios" (Latour; Venn, 2002). Si bien el fin consiste en evitar el embarazo no planificado y, sobre todo, el embarazo adolescente, tal como se señala en el documento de la FASGO, las estrategias anticonceptivas, incluyendo la disponibilidad de los métodos, no han logrado bajas 
significativas. Me pregunto entonces, ¿cuál es el fin y cuál es medio de estas intervenciones? ${ }^{10}$

Otro motivo frecuente de consulta por parte de las adolescentes se debe a las "alteraciones en el ciclo menstrual". En esta etapa, menstruar de manera regular se convierte en una prueba de no embarazo y, además, en una señal del buen funcionamiento de su aparato reproductivo:

Los trastornos del ciclo menstrual son un motivo de consulta frecuente en la adolescencia. Cuando la paciente no ha cumplido sus 3 años de edad ginecológica, podría este síntoma ser solo expresión de un estado madurativo transitorio puberal, pero también podría deberse a otras causas [...]. Es importante poder discernir lo fisiológico de lo patológico, y dentro de esto observar y tratar la causa. Las causas son múltiples [...]. No [debemos] perder la oportunidad de un diagnóstico temprano pero tampoco [tenemos que] poner una impronta en una adolescente que padece un síntoma que quizás revierta en forma espontánea. (Katabian; Oizerovich, 2017, p. 18).

\section{TRASTORNO DEL CICLO MENSTRUAL}

[...]

\section{2) ¿Cómo hacemos el abordaje?}

\section{- Anamnesis:}

El interrogatorio con la paciente y su familia [...]. Puntos que no se deben obviar: Motivo de consulta [...]

Antecedentes personales: Hábitos alimentarios y variaciones de peso - Sueño [...] - Actividad física [...] - Actividad social [...] - Existencia de conflictos familiares Rendimiento escolar - Hábitos tóxicos (tabaco, drogas, alcohol).

Antecedentes familiares

10 Nota de campo: Participé de unas jornadas tipo taller, participativas y reflexivas sobre género y salud en Atención Primaria impulsadas por médicos/as generalistas. Había alrededor de 40 profesionales, en su mayoría jóvenes. Hubo dos momentos expositivos protagonizados por una ginecóloga y una psicóloga. Después trabajamos en grupos sobre "mitos de la sexualidad". Una médica en mi grupo planteó que una de sus mayores dificultades en el consultorio era la atención de adolescentes embarazadas. "No lo soporto", dijo y pareció que todos/as entendían a que se refería. A mi me sorprendió percibir un dejo de revulsión y distancia en su modo de decirlo. A continuación, se dijeron cosas como "eso pasa porque no llegamos antes", "fallamos", "se trunca la vida de esa persona". 
Antecedentes tocoginecológicos: Edad y características de la menarca. Fecha de la última menstruación. Actitud frente a la menarca y sus menstruaciones. Ritmo menstrual. [...] Inicio de relaciones sexuales, métodos anticonceptivos. Embarazos. Partos. Abortos.

[...]

\section{- Examen físico:}

$[\ldots]$

Talla, peso, índice de masa corporal [...] y cintura. [...]

Piel [...].

Distribución grasa. [...]

Vicios posturales [...].

Examen ginecológico: Siempre evaluar si es necesario en la primera consulta o puede diferirse para mejor aceptación de la adolescente. La evaluación dependerá de si la misma ha iniciado o no relaciones sexuales [...]. (Federación Argentina de Sociedades de Ginecología y Obstetricia, 2016, p. 2-4 destacados en el original).

Si bien en los tres primeros años de "edad ginecológica" la alteración del ciclo menstrual es frecuente, su emergencia supone una alarma. En tanto manifestación tangible de la capacidad reproductiva, la menstruación se conforma como un proceso que excede al ámbito individual, íntimo y privado de las adolescentes, para transformarse en algo que compete a su entorno familiar y a la (toco)ginecología.

Los abordajes de las consultas por las alteraciones en el ciclo menstrual se inician con la anamnesis. En ese momento el médico/a recopila información de diferente índole conectando el ciclo menstrual con las incipientes experiencias sexuales de la adolescente y, también, con su estilo de vida. Como señalamos más arriba, la auto-responsabilidad es el signo con el que la (toco)ginecología marca a los cuerpos de las mujeres cis desde la adolescencia.

\section{Condensación 3: La prevención como norma del quehacer (toco)ginecológico}

El objetivo del último apartado es indagar en los efectos normativos del carácter preventivo del quehacer (toco)ginecológico. Como veremos, en buena medida, los quehaceres de esta especialidad se organizan en torno de la atención de 
mujeres cis consideradas sanas, es decir, que no manifiestan malestares ni síntomas asociados a patologías graves.

Como señalan Brown et al. (2014), la prevención se configura como una "obligación femenina básica" en el quehacer (toco)ginecológico. Esta obligación se pone de manifiesto como tal en la concurrencia efectiva de pacientes asintomáticas a los consultorios, pero también en las vidas de aquellas mujeres que no lo hacen. Recuperando los aportes de Lehner et al. (2017), la inasistencia al llamado control ginecológico es experimentada como una falta, como un malogro en el autocuidado.

Lejos de ser natural, el hecho de que las mujeres cis asistan regularmente a los controles ginecológicos es resultado, por un lado, del carácter normativo de la prevención, estrechamente conectado con regulaciones sexo-genéricas, que asocian lo preventivo con lo femenino y con el autocuidado. Por otro lado, del funcionamiento y puesta en práctica de estudios como el Papanicolaou y la Colposcopía y las maneras en las que las singularidades técnicas de estos estudios se entrelazan con los controles ginecológicos:

Las consultas más frecuentes son para el famoso control anual. Son pacientes asintomáticas que quieren controlarse. También son habituales, aunque menos, las consultas por alteraciones del ciclo menstrual y por flujo vaginal. La anticoncepción es otro motivo frecuente, dolor mamario también. (Entrevista a ginecóloga).

La consulta más frecuente es el chequeo en salud. Son pacientes sanas que vienen anualmente para controlarse. Eso habla bien de nuestra práctica, significa que hay buena llegada. Para las mujeres jóvenes los estudios clásicos son Papanicolaou y Colposcopía. A partir de los 40 se agregan la mamografía y ecografía mamaría. (Entrevista a ginecólogo).

El quehacer (toco)ginecológico se caracteriza por la atención anual de pacientes. Esta frecuencia es una disposición abstracta, independiente de, por ejemplo, la existencia o no de un proyecto reproductivo, de las características de las prácticas sexuales de quien consulta, la presencia o no de hijos/as.

En las consultas pueden tener lugar el abordaje de alguna molestia, pueden surgir dudas respecto del ciclo menstrual o en relación con la anticoncepción. 
Lo que no suele omitirse es el "control ginecológico", es decir, la realización de dos estudios: el PAP y la Colposcopía. Ambos, tienen por objetivo la prevención del cáncer de cuello de útero, uno de los pocos tipos de cáncer cuyo origen está asociado a la acción de algunas cepas del Virus Papiloma Humano (VPH). Como señalan diversos documentos, entre ellos la Guía programática abreviada para el tamizaje de cáncer cervicouterino (Argentina, 2014a) (en adelante la Guía de tamizaje):

\section{¿QUÉ SIGNIFICA TAMIZAJE?}

[...] Es un método de prevención que consiste en detectar dentro de una población sin síntomas, lesiones precancerosas. [...]

¿QUÉ ES EL PAP?

[...] es un método sencillo de tamizaje que permite detectar anormalidades celulares en el cuello del útero. [...]

HISTORIA NATURAL DEL CÁNCER DE CUELLO DE ÚTERO

Diferentes estudios han comprobado que la infección por el VPH es causa necesaria del cáncer cérvico-uterino. [...]. La infección por VPH es muy común en mujeres sexualmente activas, afecta entre el 50 y el $80 \%$ de las mujeres al menos una vez en su vida. [...]

\section{¿Qué es la Colposcopía?}

Es un examen [...] para localizar [...] las lesiones detectadas previamente con el PAP, para ser biopsiadas y diagnosticadas definitivamente. (Argentina, 2014a, p. 7, 20, destacados en el original).

Si tenemos que hablar de su importancia, es más importante el PAP, pero la Colposcopía aporta datos porque si en la Colposcopía se ve una lesión, se hace la toma del PAP sin descuidar esa lesión, para que tenga representación en la muestra. La técnica es colocar el espéculo, ver el cuello con el colposcopio y hacer la toma del PAP. (Entrevista a ginecólogo).

En nuestro país se desarrolló mucho, tenemos expertos en Colposcopía. Eso trajo como consecuencia que se traten a lo bobo un montón de lesiones que se curan solas. Manchita, biopsia, manchita, biopsia. Con el tiempo, cada vez se sabe más que esas manchitas son producto de un VPH que se cura solo. Pero bueno, hay algunos VPH malos para los que necesitamos el PAP porque muchas veces no 
producen sintomatología. Son lesiones que van progresando a lo largo de 10 años, no de un día para el otro, y pueden provocar cáncer. (Entrevista a ginecóloga).

Según la Guía de tamizaje, el cáncer de cuello de útero es una enfermedad frecuente en las mujeres cis, especialmente a partir de los cuarenta años. En tanto permite identificar la presencia del virus y tratar posibles lesiones precancerosas, la realización periódica del PAP supone una estrategia de prevención del cáncer cervicouterino. Para su realización, la paciente debe recostarse en una camilla ginecológica y abrir las piernas ante el médico/a que se ubica en el extremo de la camilla de tal modo que los genitales pasan a ser su primer plano. Se introduce el espéculo separando las paredes vaginales para permitir el acceso visual e instrumental al cuello de útero de donde se extraerá la denominada "muestra citológica". El PAP reduce circunstancialmente un término tan amplio como la prevención a la toma de una muestra de células y, de modo más general, a los cuerpos de quienes atienden a sus cuellos de útero. Asimismo, el uso regular del colposcopio, instrumento que permite observar el cuello del útero en una escala mayor, hace de este un tejido, un mosaico, cuyas irregularidades o "manchitas", modeladas a través de una especie de zoom, se traducen en alertas clínicas.

El Programa Nacional de Prevención del Cáncer Cérvico-uterino promueve la realización de PAP. Tanto la Guía de tamizaje como la Guía de intervención breve (Argentina, 2018), conforman materiales destinados a equipos de salud que alientan a la realización de PAPs no sólo a especialistas en (toco)ginecología, sino también a médicos/as de otras especialidades y a profesionales no médicos entrenados en esta técnica. Si bien el PAP es un estudio que la (toco)ginecología reclama como propio, dado que sus requerimientos técnicos son simples y que su accesibilidad supone un impacto significativo en la prevención del cáncer de cuello de útero, su realización no es exclusividad de la (toco)ginecología:

Siempre se discute si la ginecología tiene que ser Atención Primaria de la Salud o no. En otros países es más "especialidad". En nuestro país los ginecólogos manejan mucho lo que es Atención Primaria orientada a la mujer. Son dos miradas diferentes. Si la parte de Atención Primaria de la mujer la maneja el médico de familia, generalista y demás, y el ginecólogo la especialidad o si los ginecólogos también manejan la Atención Primaria. Es una discusión conflictiva, sobre 
todo cuando hay ginecólogos que creen que el PAP es su exclusividad, sabiendo que no hay ginecólogos en la mayoría de los lugares y que se trata de una técnica muy simple. Hay lugares en que al PAP lo toma un enfermero. No necesitás ser ginecólogo para hacerlo. En esos casos se hace PAP solo, sin Colpo. (Entrevista a ginecóloga).

En la implementación del PAP parecen tensionarse las fronteras disciplinarias de la (toco)ginecología. La realización conjunta del PAP y la Colposcopía añade una cuota de complejidad técnica que opera como una especie de reaseguro, apuntalando la potestad del PAP en el campo (toco)ginecológico. Cabe señalar que los documentos analizados presentan discrepancias respecto de la relevancia preventiva de la realización de la Colposcopía junto el PAP. En la Guía de tamizaje se señala que la Colposcopía debe acompañar la realización de un segundo PAP, indicado si el primero ha informado lesiones. Por el contrario, en las entrevistas, los/as médicos/as manifiestaron que la Colposcopía suele acompañar a todo PAP, independientemente de su resultado anterior y de su periodicidad.

Aunque solo algunas cepas del VPH producen lesiones potencialmente malignas mientras que otras "se curan solas", el uso permanente del colposcopio, intensifica las alertas así como el vínculo entre las mujeres cis y los controles ginecológicos sin que ello produzca más o mejores efectos a la hora de prevenir la enfermedad:

\section{POBLACIÓN OBJETIVO Y FRECUENCIA RECOMENDADA}

[...] el cáncer cervicouterino se desarrolla con mayor frecuencia en las mujeres a partir de los 40 años, llegando a un pico alrededor de los 50 años. La incidencia [...] es muy baja en las mujeres menores de 25 años. [...] Existe suficiente evidencia científica de que el tamizaje de las lesiones precursoras del cáncer cervical entre los 35 y 64 años [...] reduce la incidencia del cáncer cervical en un 80\% o más. En las mujeres menores de 35 años el tamizaje tiene menor impacto. [...]. La recomendación [...] es no tamizar a las mujeres de menos de 25 años [...]. Los posibles efectos adversos del tratamiento [...] así como las consecuencias psicológicas del tamizaje (ansiedad, angustia), pueden evitarse en las mujeres más jóvenes. [...] La frecuencia recomendada por el Programa Nacional es la realización de un Pap cada 3 años luego de dos PAPs anuales consecutivos negativos. [...] 


\section{¿CÓMO AUMENTAR LA COBERTURA DE LAS MUJERES?}

En [Argentina], el tamizaje se ha desarrollado principalmente de manera oportunística. [...] está demostrado que el PAP oportunístico tiende a concentrarse en mujeres muy jóvenes, con acceso a los servicios de salud reproductiva, que son las que menos riesgo tienen de desarrollar cáncer de cuello de útero. (Argentina, 2014a, p. 11-12, 22).

Ginecólogos/as suelen realizar PAPs y Colposcopías a mujeres jóvenes desde que comienzan a tener relaciones sexuales heterosexuales de penetración anualmente. Sin embargo, según la Guía de tamizaje, esta frecuenta no gravita necesariamente en mejoras en términos preventivos puesto que "está demostrado que el PAP oportunístico tiende a concentrarse en mujeres muy jóvenes" y que la evidencia indica que el cáncer cervicouterino se desarrolla con mayor frecuencia "a partir de los 40 años, llegando a un pico alrededor de los 50 años". Asimismo, la Guía de Tamizaje desalienta la realización de PAPs en menores de 25 años y relativiza la relevancia de su realización en mujeres menores de 35 dado el bajo impacto del tamizaje en ese grupo. De modo paradójico, quienes se realizan estos estudios con mayor regularidad son las mujeres cis jóvenes que tienen acceso al sistema de salud. Podríamos pensar que esto es resultado de la asociación entre una etapa vital como la adolescencia, identificada no sólo con el inicio de actividad sexual, sino también con la supuesta necesidad de cuidado y tutelaje, tal como vimos en relación con el abordaje de la irregularidad del ciclo menstrual.

El carácter normativo de la prevención se materializa en la dinámica regular de control, cuyos efectos exceden al tamizaje de cáncer de cuello de útero. El quehacer ginecológico compone lo que Law y Lien (2013) llaman una coreografía de prácticas, es decir, acciones que se siguen unas a otras de manera regular articulándose y conformando un hacer más o menos homogéneo. Ese hacer se organiza en torno a la prevención como principio normativo que produce relaciones entre médicos/as y pacientes con forma de control permanente. En esa continuidad se pone en juego la construcción de las mujeres cis como agentes sanitarios responsables frente al cuidado de sus familias y frente al cuidado de sí mismas y el control de su capacidad gestante y de su sexualidad que, ante todo, se conforma como reproductiva. 
La relación de las mujeres cis con la (toco)ginecología suele iniciarse en la adolescencia y se prolonga a lo largo de la adultez, en principio, sin establecer un fin, por lo menos de antemano:

Cuando hablamos de alta tiene que ver con una internación. En ginecología general nunca te dan el alta para que no tengas que volver nunca más. Los controles anuales se hacen siempre. (Entrevista a ginecólogo).

Si te operaste, sí, tenés un alta. Si estuviste internada, también. Pero en relación con los controles no. El PAP dicen que después de los 65/70, si tenías los últimos bien, podés dejar de hacértelo. Y la mamografía, en general, te la hacés más bien por... no sé. Hay un límite. Una señora de 90 años no viene a hacerse mamografías. Pero no está establecido que a tal edad puede dejar de hacérsela. Lo que pasa es que vos generas una relación con la paciente, que muchas veces viene desde la adolescencia, entonces la controlás en general. (Entrevista a ginecóloga).

La relación de las mujeres cis con la ginecología no se organiza en función de respuestas concretas frente a una dolencia o enfermedad, su tratamiento y posterior alta médica. Por el contrario, este vínculo consiste en un monitoreo permanente a lo largo de la vida que, en su desempeño ideal, prevé un inicio, pero no un fin.

\section{Conclusiones}

A lo largo del artículo se analizaron tres condensaciones ginecológicas, es decir, tres emergentes problemáticos de un campo sumamente complejo, que se encuentra atravesado por procesos de distinto alcance, temporalidad y calibre como lo es la (toco)ginecología de Buenos Aires, Argentina. Como vimos, en esta especialidad se entrecruzan cuestiones heterogéneas que van desde regulaciones biopolíticas orientadas al control de la maternidad y la natalidad, hasta las agencias asociadas a dispositivos técnicos tales como los colposcopios. También analizamos cómo se articulan los distintos niveles estatales que gobiernan lo sanitario en el territorio local, sus dinámicas y objetivos respecto tanto de la orientación del perfil profesional, como de las abundantes políticas 
y programas enfocados en lo sexual y reproductivo. Además, indagamos en las maneras en las que las materialidades heterogeneas de los cuerpos de las mujeres cis y sus múltiples formas de vida y contextos se entrelazan con el funcionamiento de regulaciones de género y con la productividad de nociones como las de prevención y (auto)cuidado. Analizamos también distintas aperturas y cierres asociados a dispositivos técnicos que intervienen en los quehaceres médicos, tales como guías de prácticas clínicas, pautas para la realización de entrevistas, anticonceptivos o el PAP. Además, vimos cómo intervienen las emociones y el cansancio de quienes atienden, así como las limitaciones prácticas que suponen el funcionamiento de las instituciones sanitarias. Pues, todo esto conforma y forma parte del intenso campo de la (toco)ginecología.

Las tres condensaciones ginecológicas analizadas supusieron la detección, organización y confección de emergentes problemáticos concretos y parciales. En el artículo no se analizó a la tocoginecología, en general. Se analizaron tres nudos problemáticos en los que se entrelazan aspectos políticos, epistemológicos, prácticos y ontológicos.

La primera condensación analizada se vincula con la producción de "la salud integral de la mujer" como objeto clínico. Este objeto resulta de un ejercicio de reducción y amplificación en el cual las definiciones generales de este campo médico, especialmente aquellas relacionadas a "la mujer" como ideal regulatorio, se moldean junto a los procesos de salud y las características corporales singulares de las mujeres que consultan. La (toco)ginecología produce a la "salud de la mujer" como objeto clínico homogéneo y regular y, al mismo tiempo, define a las mujeres cis a través de las capacidades reproductivas de su corporalidad.

La segunda condensación, refiere al modo en el que las mujeres cis se convierten en pacientes (toco)ginecológicas y a la producción, a través de distintos hitos clínicos, de sus trayectorias vitales en términos de "ciclos", regulares y normativos, organizados en torno a lo reproductivo. El proceso de convertirse en paciente ginecológica suele coincidir con la llegada de la menarca y/o con el inicio de las relaciones sexuales heterosexuales. En su vínculo con los consultorios (toco)ginecológicos, los cuerpos de las adolescentes se conforman como reproductivos, significados y mediados, por su relación con la penetración vaginal y por las prácticas asociadas a la prevención y el (auto)cuidado.

La tercera condensación consiste en los efectos normativos del énfasis preventivo propio del quehacer ginecológico. En otras palabras, se trata de la 
sedimentación de los efectos normativos del género, de la prevención y del cuidado, que dan forma al control ginecológico, es decir, a la asistencia regular a los consultorios y a la realización de PAPs y Colposcopías. Se analizaron las maneras en las que la idea de prevención se encastra y potencia con el uso de instrumentos técnicos como es el caso del colposcopio. También se indagó en las maneras en las que el PAP se pone en juego en las definiciones y fronteras disciplinarias de la (toco)ginecología, además de su relevancia en los controles en salud y sus efectos en la regulación de la sexualidad, especialmente de las mujeres cis jóvenes.

A modo de conclusión, quisiera resaltar los efectos materiales de las distintas regulaciones que se operacionalizan en el quehacer de la (toco)ginecología respecto de los cuerpos de las mujeres cis. Como vimos, en el campo de esta especialidad conviven la promoción de un abordaje integral de la salud, con la atención concreta y suscinta, circunscripta a la demanda de las pacientes. Ambas formas de concebir y organizar el quehacer clínico de la (toco)ginecología están relacionadas con la suposición de que las vidas de las mujeres cis se organizan en etapas progresivas, que los ápices de sus trayectorias vitales estarían dados por el embarazo y el parto, y que sus corporalidades son homogéneas. Pues, de una manera u otra, buena parte de los quehaceres (toco)ginecológicos se orientan al control y resguardo de las capacidades gestantes de las mujeres cis, en tanto mujeres cis y no en tanto portadoras de cuerpos neutrales y ahistóricos con úteros, ovarios, vaginas y mamas. El campo (toco)ginecológico aborda los procesos vinculados a cuestiones genito-mamarias en tanto forman parte de una articulación mayor, dada por la categoría de "mujer". En esa articulación se entrelazan "mujer", "(auto)cuidado", "control" y "prevención", operación normativa cuyos efectos regulan, de manera inacabada, la producción material de los cuerpos de las mujeres cis.

\section{Referencias}

ARGENTINA. Ministerio de Salud. Guía para la atención del parto normal en maternidades centradas en la familia. Buenos Aires: MS, 2010a. Disponible en: https://bancos. salud.gob.ar/sites/default/files/2018-10/0000000239cnt-g09.guia-atencion-parto-normal.pdf. Acceso: 20 sept. 2020. 
ARGENTINA. Ministerio de Salud. Marco de referencia para la formación en Residencias Médicas: especialidad Tocoginecología. Buenos Aires: Subsecretaría de Políticas, Regulación y Fiscalización: Secretaria de Políticas, Regulación e Institutos, 2010b. Disponible en: https://www.argentina.gob.ar/sites/default/files/tocoginecologia.pdf. Acceso: 20 sept. 2020.

ARGENTINA. Ministerio de Salud. Protocolo para la atención integral de las personas con derecho a la interrupción voluntaria y legal del embarazo. Buenos Aires: MS, 2010c. Disponible en: https://bancos.salud.gob.ar/sites/default/files/2021-05/protocolo-IVE_ILE-2021-26-05-2021.pdf. Acceso: 30 sept. 2021.

ARGENTINA. Ministerio de Salud. Protocolo para la atención integral de personas víctimas de violaciones sexuales. Buenos Aires: MS, 2011. Disponible en: https://bancos.salud. gob.ar/sites/default/files/2021-08/Protocolo_VVS_2021.pdf. Acceso: 30 sept. 2021.

ARGENTINA. Ministerio de Salud. Guía programática abreviada para el tamizaje de cáncer cervicouterino. Buenos Aires: MS, 2014a. Disponible en: https://bancos.salud. gob.ar/sites/default/files/2018-10/0000000433cnt-guia_programatica_abreviada_ baja.pdf. Acesso: 20 sept. 2020.

ARGENTINA. Ministerio de Salud. Métodos anticonceptivos: guía práctica para profesionales de la salud. Buenos Aires: MS, 2014b. Disponible en: https://bancos.salud.gob. ar/sites/default/files/2021-09/Guia_MAC_con_errata_2021.pdf. Acceso: 30 sept. 2021.

ARGENTINA. Ministerio de Salud. Guía de intervención breve “Un momento para hablar del PAP”. Buenos Aires: MS, 2018. Disponible en: https://bancos.salud.gob.ar/sites/ default/files/2018-10/0000000432cnt-guia_intervencion_breve_un_momento_ para_hablar_del_pap.pdf. Acceso: 20 sept. 2020.

ARGENTINA. Ministerio de Salud. Materiales para equipos de salud. Buenos Aires: Subsecretaría de Gobierno Abierto y País Digital, [2020a]. Disponible en: http://bancos.salud.gob.ar/bancos/materiales-para-equipos-de-salud?field_problematica_target_id=92\&field_soporte_target_id=All\&title=. Acceso: 20 sept. 2020.

ARGENTINA. Ministerio de Salud. Sistema Nacional de Acreditación de Residencias del Equipo de Salud (SNARES). Buenos Aires: Subsecretaría de Gobierno Abierto y País Digital, [2020b]. Disponible en: https://www.argentina.gob.ar/salud/residencias/ acreditaciones. Acceso: 20 sept. 2020.

ARGENTINA. Ministerio de Salud. Instituto Nacional del Cáncer. Programa Nacional de Prevención de Cáncer Cervicouterino. Buenos Aires: Subsecretaría de Gobierno Abierto y País Digital, [2020c]. Disponible en: https://www.argentina.gob.ar/salud/ instituto-nacional-del-cancer/institucional/pnpcc\#: :text=El\%20PNPCC\%20 forma\%20parte\%20de,PAP\%20o\%20test\%20de\%20VPH. Acceso: 20 sept. 2020. 
ARIZA, L. Fotografías, registrosmédicos y la produccion material del parentesco: Acerca de la coordinación fenotípica en la reproducción asistida en Argentina. In: CEPEDA, A.; RUSTOYBURU, C. (ed.). De las hormonas sexuadas al viagra: ciencia, medicina y sexualidad en Argentina y Brasil. Mar del Plata: EUDEM, 2014. p. 130-158.

ARIZA, L. No pagarás: El Consentimiento Informado como productor de solidaridad en la medicina reproductiva. Ciencia, Docencia y Tecnología, [s. l.], n. 52, p. 240-268, 2016.

ASOCIACIÓN PARA LAS NACIONES UNIDAS DE LA REPÚBLICA ARGENTINA. LoS Objetivos de Desarrollo del Milenio, propuesta ONU. [S. l.]: ANU-AR, 2016. Disponible en: https://www.anu-ar.org/notas/objetivos-de-desarrollo-del-milenio.html\#: :text=En\%20la\%20Declaraci\%C3\%B3n\%20del\%20Milenio,el\%20sustento\%20del\%20 medio\%20ambiente. Acceso: 20 sept. 2020.

BARAD, K. Diffracting diffraction: cutting together-apart. Parallax, [s. l.], v. 20, n. 3, p. 168-187, 2014. DOI: https://doi.org/10.1080/13534645.2014.927623.

BOURDIEU, P. La dominación masculina. Barcelona: Anagrama, 2000.

BRAH, A. Diferencia, diversidad y diferenciación. In: HOOKS, B. et al. (ed.). Otras inapropiables: feminismos desde las fronteras. Madrid: Traficantes de Sueños, 2004. p. 107-133.

BROWN, J. Los derechos (no) reproductivos y sexuales en los bordes entre lo público y lo privado. Algunos nudos del debate en torno a la democratización de la sexualidad. Sexualidad, Salud y Sociedad: revista latinoamericana, Rio de Janeiro, n. 2, p. 10-28, 2009. Disponible en: http://www.redalyc.org/articulo.oa?id=293322969002. Acceso: 20 sept. 2020.

BROWN, J. et al. Cuerpo, sexo y reproducción. La noción de autonomía de las mujeres puesta en cuestión: el aborto y otras situaciones sensibles. Revista Latinoamericana de Estudios sobre Cuerpos, Emociones y Sociedad, [s. l.], v. 2, n. 12, p. 37-50, 2013 a.

BROWN, J. et al. Género, cuerpo y sexualidad en la atención ginecológica. Revista Artemis, [s. l.], v. 15, n. 1, p. 135-149, 2013b.

BROWN, J. et al. Atención ginecológica de lesbianas y bisexuales: notas sobre el estado de situación en Argentina. Interface - Comunicação, Saúde, Educação, Botucatu, v. 18, n. 51, p. 673-684, 2014.

BUTLER, J. El género en disputa: el feminismo y la subversión de la identidad. Buenos Aires: Paidós, 2007.

CABRAL, M. Cisexual. In: CABRAL, M. (comp.). Construyéndonos. [S. l.]: Mulabi, Espacio Latinoamericano de Sexualidades y Derechos, [2009]. p. 48. 
CIUDAD AUTÓNOMA DE BUENOS AIRES. Ministerio de Salud. Programa docente de la Residencia de Tocoginecología. Buenos Aires: MS, 2012. Disponible en: https:// www.buenosaires.gob.ar/sites/gcaba/files/programa_de_residencia_de_tocogineco_-_caba.pdf. Acceso: 20 sept. 2020.

COSTA, T. et al. Naturalization and medicalization of the female body: Social control through reproduction. Interface - Comunicação, Saúde, Educação, Botucatu, v. 10, n. 20, p. 363-380, 2006. DOI: https://doi.org/10.1590/S1414-32832006000200007.

DE LAURETIS, T. La tecnología del género. In: DE LAURETIS, T. Technologies of gender: essays on theory, film and fiction. London: Macmillan Press, 1989. p. 1-30.

DELEUZE, G.; GUATTARI, F. Mil mesetas: capitalismo y esquizofrenia. Valencia: Pre-Textos, 2010.

FAUSTO-STERLING, A. Cuerpos sexuados: la política de género y la construcción de la sexualidad. Madrid: Melusina, 2006.

FEDERACIÓN ARGENTINA DE SOCIEDADES DE GINECOLOGÍA Y OBSTETRICIA. Consenso de ginecología infanto-juvenil: trastornos del ciclo menstrual, prevención del embarazo en la adolescencia, infección por HPV. Buenos Aires: FASGO, 2016. Disponible en: http://www.fasgo.org.ar/archivos/consensos/Consenso_de_Ginecologia_infantojuvenil_Actualizacion.pdf. Acceso: 20 sept. 2020.

FEDERACIÓN ARGENTINA DE SOCIEDADES DE GINECOLOGÍA Y OBSTETRICIA. Manejo terapéutico del carcinoma de cuello uterino. Buenos Aires: FASGO, 2017a. Disponible en: http://www.fasgo.org.ar/archivos/consensos/Consenso_MANEJO_TERAPEUTICO_DEL_CARCINOMA_DE_CUELLO_UTERINO.pdf. Acceso: 20 sept. 2020.

FEDERACIÓN ARGENTINA DE SOCIEDADES DE GINECOLOGÍA Y OBSTETRICIA. Vacunas contra Virus del Papiloma Humano. Buenos Aires: FASGO, 2017b. Disponible en: http://www.fasgo.org.ar/archivos/consensos/Actualizacion_Consenso_Vacunas_ HPV_FASGO_2017.pdf. Acceso: 20 sept. 2020.

FEDERACIÓN ARGENTINA DE SOCIEDADES DE GINECOLOGÍA Y OBSTETRICIA. Preservación de la fertilidad. Buenos Aires: FASGO, 2018. Disponible en: http://www. fasgo.org.ar/archivos/consensos/Actualizacion_Consenso_FASGO_2018_Preservacion_de_la_fertilidad.pdf. Acceso: 20 sept. 2020.

FOUCAULT, M. Microfísica del poder. Buenos Aires: La Piqueta, 1992.

FOUCAULT, M. Historia de la sexualidad: la voluntad de saber. Buenos Aires: Siglo XXI, 2002.

FOUCAULT, M. La vida de los hombres infames: ensayos sobre desviación y dominación. Buenos Aires: Caronte Ensayos, 2008.

FREITAS, P. "A mulher é seu útero". A criação da moderna medicina feminina no Brasil. Antíteses, Londrina, v. 1, n. 2, p. 174-187, 2008. 
GIURGIOVICH, A. Adolescencia, ¿una consulta distinta? Revista de la Sociedad de Obstetricia y Ginecología de la Provincia de Buenos Aires, Buenos Aires, v. 48, n. 238, p. 12-14, 2017. Disponible en: http://www.sogba.org.ar/Revista_SOGBA2017_1/index. html\#p=17. Acceso: 20 sept. 2020.

HARAWAY, D. Ciencia, cyborgs y mujeres: la reinvención de la naturaleza. Madrid: Universitat de València, 1995.

HOLLAND-HALL, C. Sangrado menstrual abundante en adolescentes, ¿se trata de una variante normal o de un trastorno hemorrágico?. Traducción M. Ladino y C. Ciochi. Revista de la Sociedad de Obstetricia y Ginecología de la Provincia de Buenos Aires, Buenos Aires, v. 49, n. 242, p. 29-35, 2018. Disponible en: http://www.sogba.org.ar/ Revista_SOGBA2018_1/mobile/index.html\#p=33. Acceso: 20 sept. 2020.

HOSPITAL ITALIANO DE BUENOS AIRES. Programa de Residencia en Tocoginecología. Buenos Aires: Hospital Italiano de Buenos Aires, [2008]. Disponible en: https:// www.hospitalitaliano.org.ar/multimedia/archivos/cursos_attachs/4092.pdf. Acceso: 20 sept. 2020.

KATABIAN, L.; OIZEROVICH, S. Trastornos del ciclo menstrual. Prevención del embarazo en la adolescencia. Infección por VPH. FASGO Ciencia - Informa. Buenos Aires, v. 16, n. 1, p. 13-31, 2017. Disponible en: http://www.fasgo.org.ar/images/1-2017. pdf. Acceso: 20 sept. 2020.

LASH, S. Sociología del posmodernismo. Buenos Aires: Amorrortu, 2007.

LATOUR, B. La esperanza de Pandora: ensayos sobre la realidad de los estudios de la ciencia. Barcelona: Gedisa, 2001.

LATOUR, B. Reensamblar lo social: una introducción a la teoría del actor-red. Buenos Aires: Manantial, 2008.

LATOUR, B.; VENN, C. Morality and technology. Theory, Culture \& Society, [s. l.], v. 19, n. 5-6, p. 247-260, 2002. DOI: https://doi.org/10.1177/026327602761899246.

LAW, J. STS as method. [S. l: s. n], 2015. Disponible en: http://heterogeneities.net/publications/Law2015STSAsMethod.pdf. Acceso: 20 sept. 2020.

LAW, J.; LIEN, M. Slippery: field notes in empirical ontology. Social Studies of Science, [s. l.], v. 43, n. 3, p. 363-378, 2013. DOI: https://doi.org/10.1177/0306312712456947.

LEHNER, P. et al. Cuidados y descuidos: percepciones sobre el auto-cuidado de la salud de dos generaciones de mujeres del gran Buenos Aires. Symploké: revista filosófica, Buenos Aires, n. 7, p. 82-89, 2017. Disponible en: http://www.revistasymploke. com/revistas/SymplokeN7.pdf. Acceso: 20 sept. 2020. 
LYKKE, N. This discipline which is not one: feminist studies as a post-discipline. In: BUIKEMA, R.; GRIFFIN, G.; LYKKE, N. (ed.). Theories and methodologies in postgraduate feminist research: researching differently. New York : Routledge, 2012. p. 137-150.

MACHEREY, P. De Canguilhem a Foucault: la fuerza de las normas. Buenos Aires: Amorrortu, 2011.

MALUF, S. Gênero, saúde e aflição: políticas públicas, ativismo e experiências sociais. In: MALUF, S.; TORNQUIST, C. (org.). Gênero, saúde e aflição: abordagens antropológicas. Florianópolis: Letras Contemporâneas, 2010. p. 21-67.

MARTIN, E. A mulher no corpo: uma análise cultural da reprodução. Rio de Janeiro: Garamond, 2006.

MINES CUENYA, A. Prácticas médico-clínicas y ontologías corporales: sus relaciones entre los campos de la ginecología, la urología y la sexología médica en Buenos Aires. 2019. Tesis (Doctorado en Ciencias Sociales) - Facultad de Ciencias Sociales, Universidad de Buenos Aires, Buenos Aires, 2019.

MOL, A. The body multiple: ontology in medical practice. Durham: Duke University Press, 2002.

MOL, A. Mind your plate! The ontonorms of Dutch dieting. Social Studies of Science, [s. l.], v. 43, n. 3, p. 379-396, 2013. DOI: https://doi.org/10.1177/0306312712456948.

MOL, A. Who knows what a woman is... On differences and the relations between the sciences. Medicine Anthopology Theory, [s. l.], v. 2, n. 1, p. 57-75, 2015. DOI: https:// doi.org/10.17157/mat.2.1.215.

MOL, A.; LAW, J. Embodied action, enacted bodies. The example of hypoglycaemia. Body \& Society, [s. l.], v. 10, n. 2-3, p. 43-62, 2004.

PRECIADO, P. Testo yonqui. Buenos Aires: Paidós, 2014.

PROVINCIA DE BUENOS AIRES. Ministerio de Salud. Guía para personal de salud sobre salud sexual y reproductiva y prevención de la violencia hacia la población LGBT. Buenos Aires: MS, 2012a. Disponible en: http://www.ms.gba.gov.ar/sitios/tocoginecologia/files/2014/02/Guia-para-el-Personal-de-Salud-sobre-Salud-Sexual-y-Reproductiva-y-Prevencion-de-la-Violencia-hacia-poblacion-LGTB.pdf. Acceso: 20 sept. 2020 .

PROVINCIA DE BUENOS AIRES. Ministerio de Salud. Programa de Residencias: Tocoginecología. Buenos Aires: MS, [2012b]. Disponible en: http://www.ms.gba.gov.ar/ ssps/residencias/programas/Tocoginecologia.pdf. Acceso: 20 sept. 2020. 
RADEMACHER, K. et al. Los cambios en el sangrado menstrual son NORMALES: Herramienta de asesoramiento propuesta para abordar las razones comunes de la falta de uso y la interrupción de la anticoncepción. Revista AMAdA, Buenos Aires, v. 14, n. 2, 2018. Disponible en: http://www.amada.org.ar/index.php/revista/numeros-anteriores/volumen-14-n-2-2018/260. Acceso: 20 sept. 2020.

ROHDEN, F. Uma ciência da diferença: sexo e gênero na medicina da mulher. Rio de Janeiro: Fiocruz, 2001. Disponible en: http://static.scielo.org/scielobooks/8m665/ pdf/rohden-9788575413999.pdf. Acceso: 20 sept. 2020.

ROHDEN, F. Medicina, Estado y reproducción en el Brasil de inicios del siglo XX. Íconos: revista de ciencias sociales, Quito, n. 28, p. 47-57, mayo 2007. Disponible en: https://repositorio.flacsoandes.edu.ec/bitstream/10469/611/4/RFLACSO-I28-05-Rohden.pdf. Acceso: 20 sept. 2020.

ROHDEN, F. Histórias e tensões em torno da medicalização da reprodução. Gênero, Niterói, v. 6, n. 1, p. 213-224, 2012. Disponible en: https://periodicos.uff.br/revistagenero/article/view/31017. Acceso: 20 sept. 2020.

SCHWARZ, P. Construcción de la maternidad en el encuentro de la institución médico ginecológica con mujeres de clase media de la ciudad de Buenos Aires. Sexualidad, Salud y Sociedad: revista latinoamericana, Rio de Janeiro, n. 6, p. 83-104, 2010.

TAMBURRINO, C. et al. Cuerpo, sexualidad y 'cosas de mujeres'. Un análisis de la atención ginecológica. In: JORNADA DE JÓVENES INVESTIGADORES, 4., 2007, Buenos Aires. Actas [...]. Buenos Aires: Universidad de Buenos Aires, 2007. Disponible en: https://www.aacademica.org/000-024/174.pdf. Acceso: 20 sept. 2020.

TILLI, M. ¿Qué debemos saber sobre HPV? ASAIGO-ITS, Buenos Aires, [2015a]. Disponible en: https://www.asaigoits.org.ar/index.php/comunidad/159-que-debemos-saber-del-hpv. Acceso: 20 sept. 2020.

TILLI, M. ¿Qué es la vaginosis bacteriana? ASAIGO-ITS, Buenos Aires, [2015b]. Disponible en: https://www.asaigoits.org.ar/index.php/comunidad/161-que-es-la-vaginosis-bacteriana. Acceso: 20 sept. 2020.

UNIVERSIDAD DE BUENOS AIRES. Facultad de Medicina. Programa de Ginecología. Buenos Aires: UBA, 2014. Disponible en: https://www.fmed.uba.ar/sites/default/ files/2018-03/progr_gineco_1.pdf. Acceso: 20 sept. 2020.

VIEIRA, E. A medicalização do corpo feminino. Rio de Janeiro: Fiocruz, 2002.

Recebido: 29/09/2020 Aceito: 06/07/2021 | Received: 9/29/2020 Accepted: 7/6/2021 